Network Working Group

Request for Comments: 1243
S. Waldbusser, Editor Carnegie Mellon University July 1991

\title{
AppleTalk Management Information Base
}

Status of this Memo

This memo defines objects for managing AppleTalk objects for use with the SNMP protocol. This memo is a product of the AppleTalk-IP Working Group of the Internet Engineering Task Force (IETF). This RFC specifies an IAB standards track protocol for the Internet community, and requests discussion and suggestions for improvements. Please refer to the current edition of the "IAB Official Protocol Standards" for the standardization state and status of this protocol. Distribution of this memo is unlimited.

Table of Contents

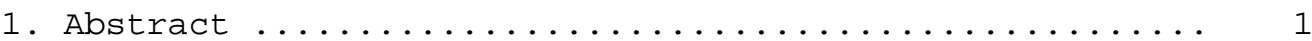

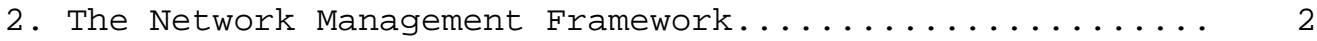

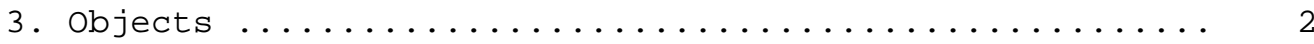

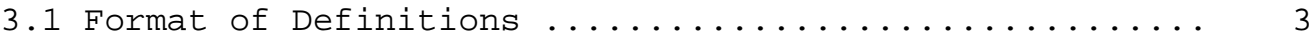

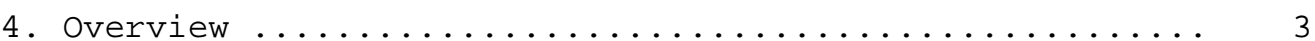

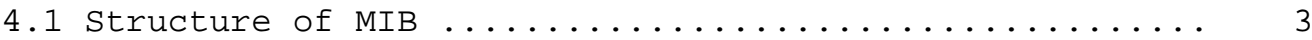

4.2 The LocalTalk Link Access Protocol Group ............ 3

4.3 The AppleTalk Address Resolution Protocol Group ...... 4

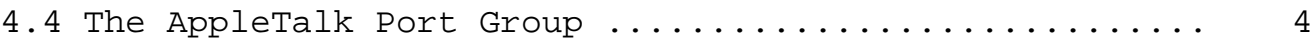

4.5 The Datagram Delivery Protocol Group .............. 4

4.6 The Routing Table Maintenance Protocol Group ........ 4

4.7 The Kinetics Internet Protocol Group .............. 4

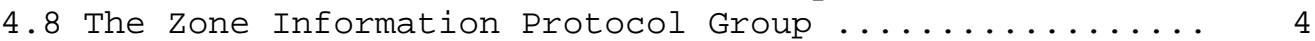

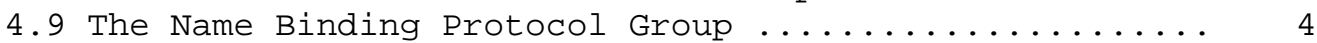

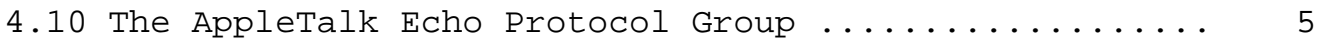

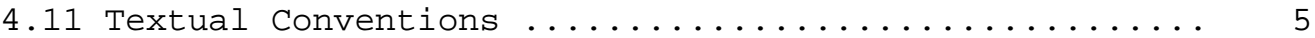

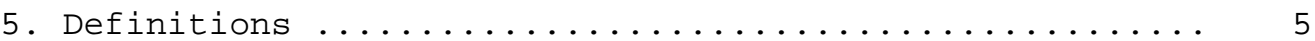

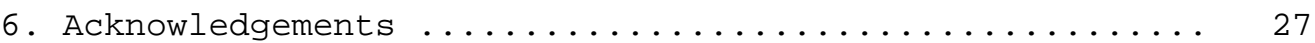

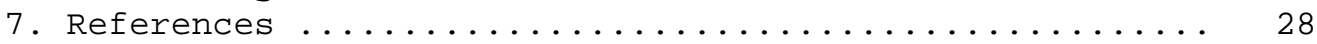

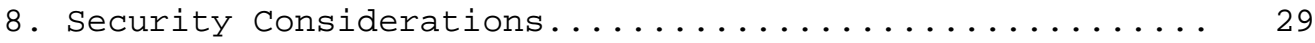

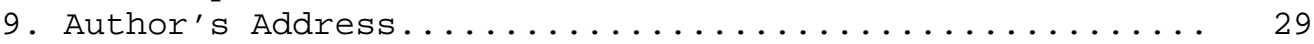

1. Abstract

This memo defines a portion of the Management Information Base (MIB) for use with network management protocols in TCP/IP-based internets. In particular, it defines objects for managing AppleTalk networks. 
2. The Network Management Framework

The Internet-standard Network Management Framework consists of three components. They are:

RFC 1155 which defines the SMI, the mechanisms used for describing and naming objects for the purpose of management. RFC 1212 defines a more concise description mechanism, which is wholly consistent with the SMI.

RFC 1156 which defines MIB-I, the core set of managed objects for the Internet suite of protocols. RFC 1213, defines MIB-II, an evolution of MIB-I based on implementation experience and new operational requirements.

RFC 1157 which defines the SNMP, the protocol used for network access to managed objects.

The Framework permits new objects to be defined for the purpose of experimentation and evaluation.

3. Objects

Managed objects are accessed via a virtual information store, termed the Management Information Base or MIB. Objects in the MIB are defined using the subset of Abstract Syntax Notation One (ASN.1) [7] defined in the SMI. In particular, each object has a name, a syntax, and an encoding. The name is an object identifier, an administratively assigned name, which specifies an object type. The object type together with an object instance serves to uniquely identify a specific instantiation of the object. For human convenience, we often use a textual string, termed the OBJECT DESCRIPTOR, to also refer to the object type.

The syntax of an object type defines the abstract data structure corresponding to that object type. The ASN.1 language is used for this purpose. However, the SMI [3] purposely restricts the ASN.1 constructs which may be used. These restrictions are explicitly made for simplicity.

The encoding of an object type is simply how that object type is represented using the object type's syntax. Implicitly tied to the notion of an object type's syntax and encoding is how the object type is represented when being transmitted on the network.

The SMI specifies the use of the basic encoding rules of ASN.1 [8], subject to the additional requirements imposed by the SNMP. 


\subsection{Format of Definitions}

Section 5 contains the specification of all object types contained in this MIB module. The object types are defined using the conventions defined in the SMI, as amended by the extensions specified in [9, 10].

4. Overview

AppleTalk is a protocol suite which features an open peer-to-peer architecture that runs over a variety of transmission media.

AppleTalk is defined in [10]. This protocol suite interoperates with the IP protocol suite through various encapsulation methods. As large AppleTalk networks are built that coexist with large IP networks, a method to manage the AppleTalk networks with SNMP becomes necessary. This MIB defines managed objects to be used for managing AppleTalk networks.

4.1. Structure of MIB

The objects are arranged into the following groups:

$$
\begin{aligned}
& \text { - LLAP } \\
& \text { - AARP } \\
& \text { - ATPort } \\
& \text { - DDP } \\
& \text { - RTMP } \\
& \text { - KIP } \\
& \text { - ZIP } \\
& \text { - NBP } \\
& \text { - ATEcho }
\end{aligned}
$$

These groups are the basic unit of conformance. If the semantics of a group is applicable to an implementation, then it must implement all objects in that group. For example, a managed agent must implement the KIP group if and only if it implements the KIP protocol.

These groups are defined to provide a means of assigning object identifiers, and to provide a method for managed agents to know which objects they must implement.

\subsection{The LocalTalk Link Access Protocol Group}

The LocalTalk Link Access Protocol (LLAP) is a medium-speed data-link protocol designed for low cost and plug-and-play operation. The LLAP group is designed to manage all interfaces on a managed device that use this protocol. 


\subsection{The AppleTalk Address Resolution Protocol Group}

The AppleTalk Address Resolution Protocol (AARP) is used to map between AppleTalk node addresses, used by the Datagram Delivery Protocol, and the addresses of the underlying data link layer. The AARP table allows for management of the Address Mapping Table on the managed device.

\subsection{The AppleTalk Port Group}

An AppleTalk Port is a logical connection to a network over which AppleTalk packets can be transmitted. This group allows the management of the configuration of these AppleTalk ports.

4.5. The Datagram Delivery Protocol Group

The Datagram Delivery Protocol (DDP) is the network-layer protocol that is responsible for the socket-to-socket delivery of datagrams over the AppleTalk Internet. This group manages the DDP layer on the managed device.

\subsection{The Routing Table Maintenance Protocol Group}

The Routing Table Maintenance Protocol (RTMP) is used by AppleTalk routers to create and maintain the routing tables that dictate the process of forwarding datagrams on the AppleTalk internet. The RTMP group manages the RTMP protocol as well as the routing tables generated by this protocol.

\subsection{The Kinetics Internet Protocol Group}

The Kinetics Internet Protocol (KIP) is a protocol for encapsulating and routing AppleTalk datagrams over an IP internet. This name is historical. The KIP group manages the KIP routing protocol as well as the routing tables generated by this protocol.

\subsection{The Zone Information Protocol Group}

The Zone Information Protocol (ZIP) is used to maintain a mapping between networks and zone names to facilitate the name lookup process performed by the Name Binding Protocol. The ZIP group manages this protocol and the mapping it produces.

\subsection{The Name Binding Protocol Group}

The Name Binding Protocol (NBP) is a transport-level protocol that is used to convert human readable service names into the numeric AppleTalk network addresses needed for communicating across the 
AppleTalk network. The NBP group manages this protocol and the NBP services that exist on the managed device.

4.10. The AppleTalk Echo Protocol Group

The AppleTalk Echo Protocol is a transport-level protocol used to test and verify the status of the AppleTalk internet. The AtEcho group manages this protocol.

4.11. Textual Conventions

A new data type is introduced as a textual convention in this MIB document. This textual convention enhances the readability of the specification and can ease comparison with other specifications if appropriate. It should be noted that the introduction of this textual convention has no effect on either the syntax or the semantics of any managed objects. The use of this is merely an artifact of the explanatory method used. Objects defined in terms of this method are always encoded by means of the rules that define the primitive type. Hence, no changes to the SMI or the SNMP are necessary to accommodate this textual convention which is adopted merely for the convenience of readers and writers in pursuit of the elusive goal of clear, concise, and unambiguous MIB documents.

The new data type is:

$$
\begin{aligned}
& \text { DdpAddress : := } \quad--2 \text { octets of net number, } \\
& \text { OCTET STRING (SIZE (3)) } \\
& --1 \text { octet of node number }
\end{aligned}
$$

5. Definitions

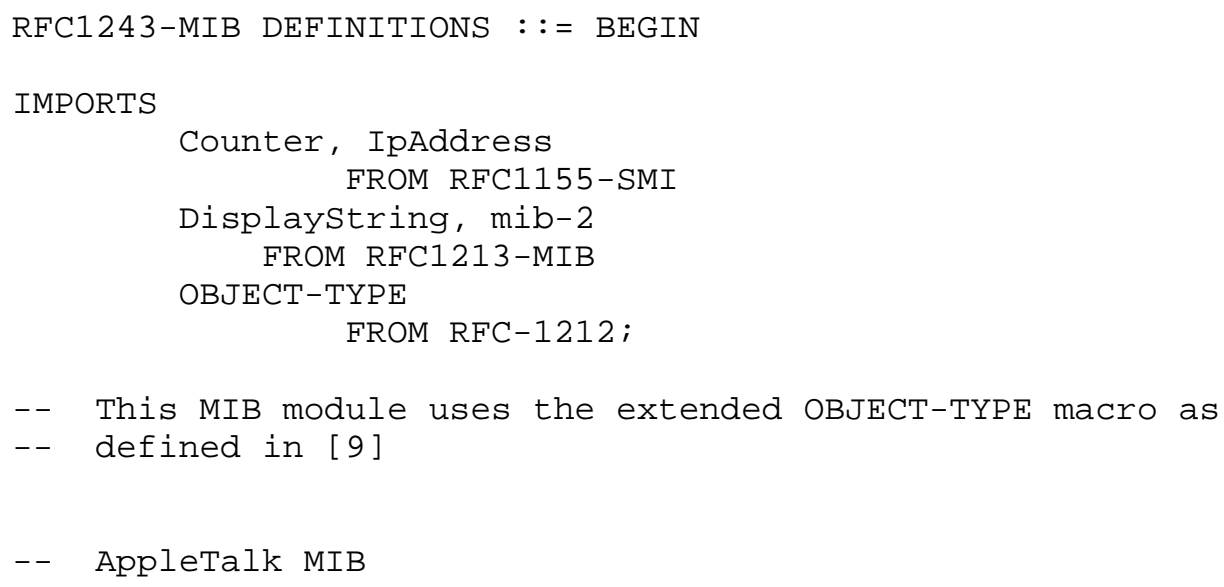




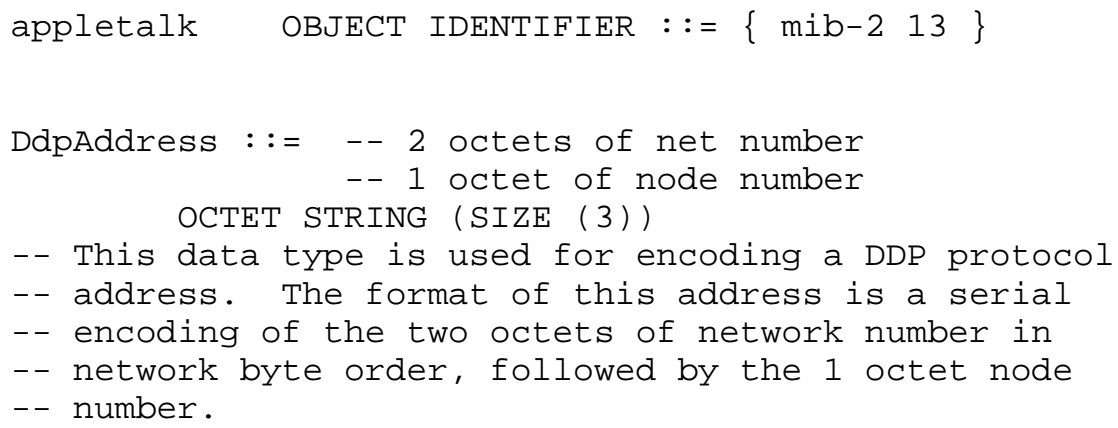




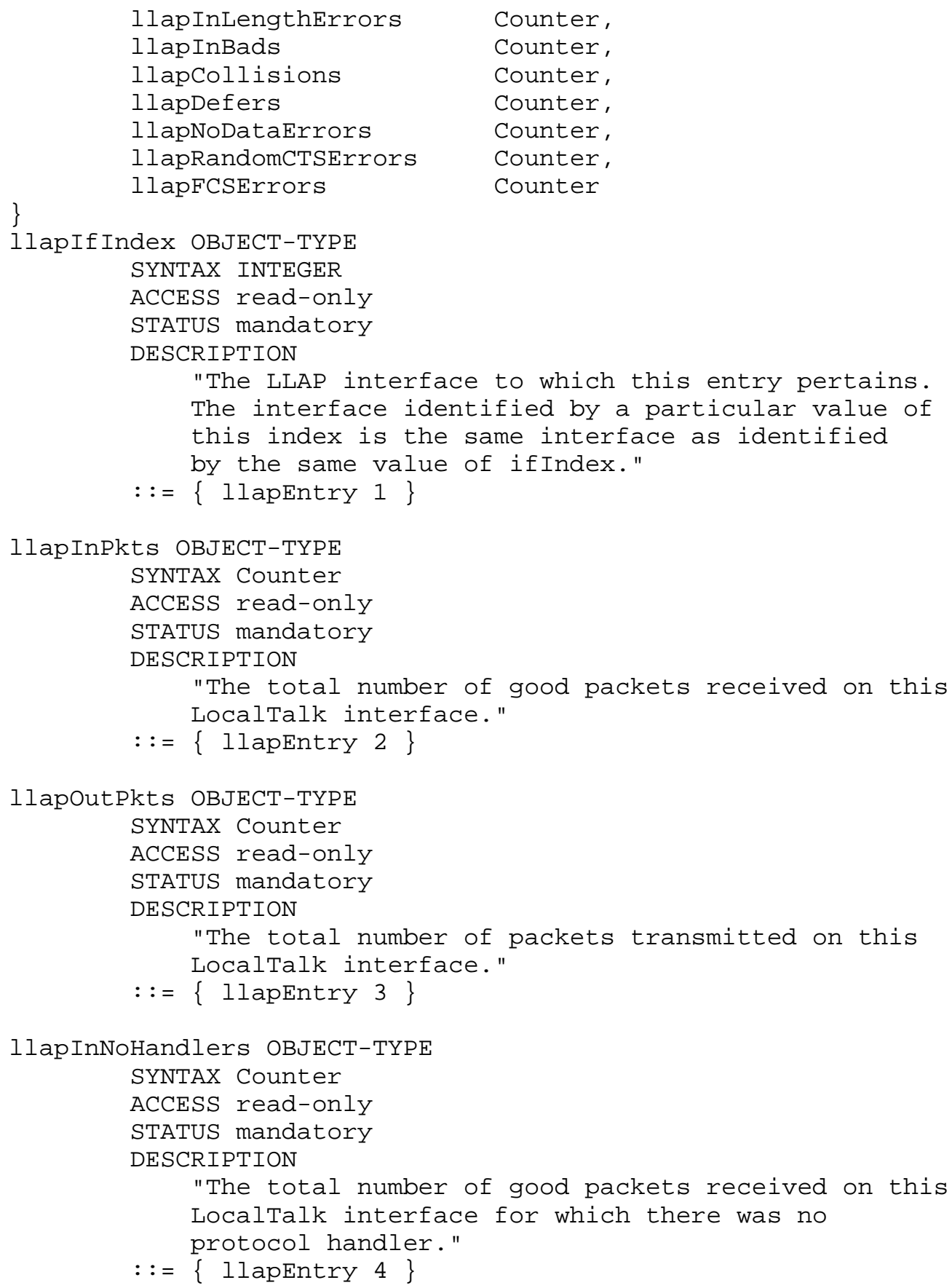




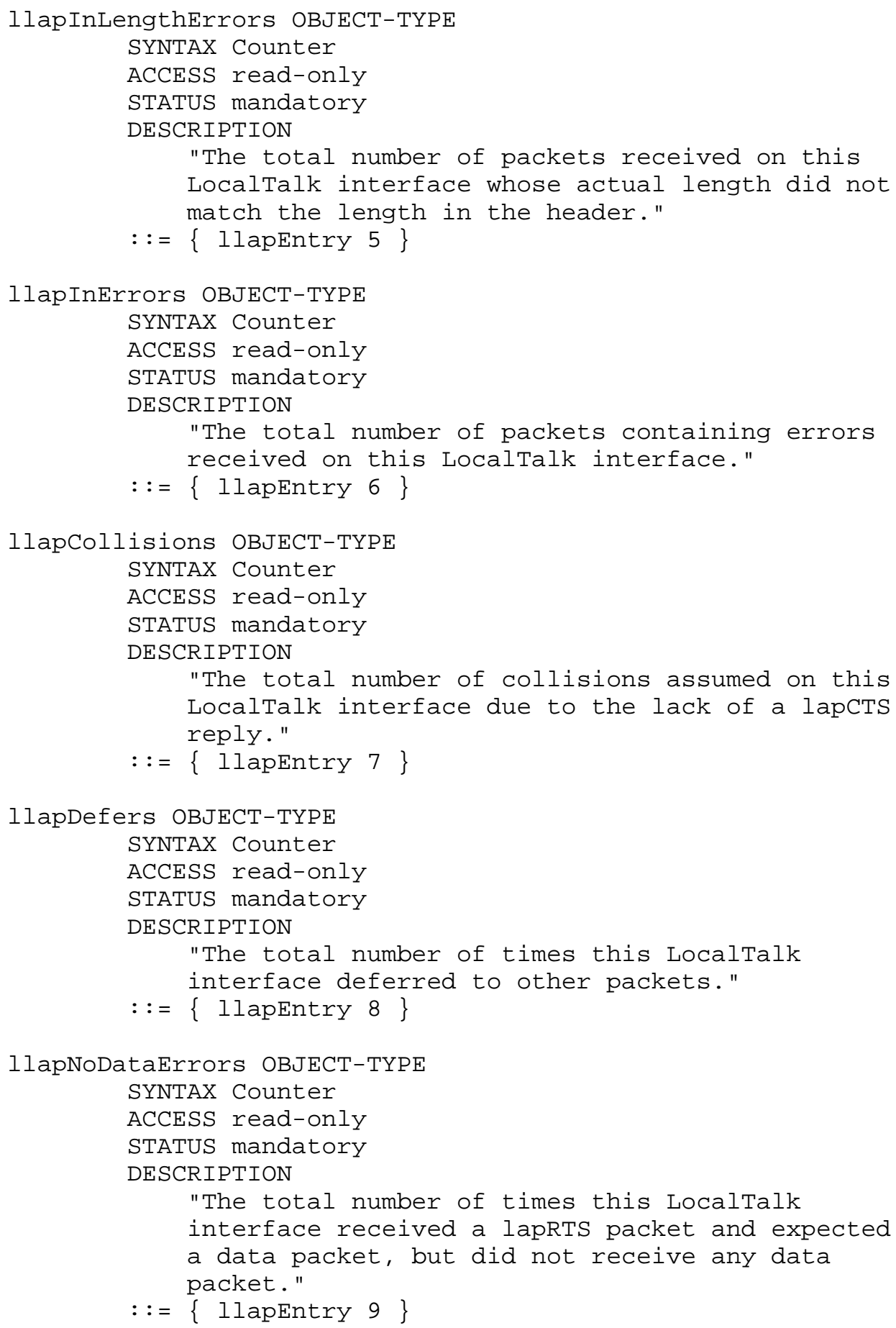




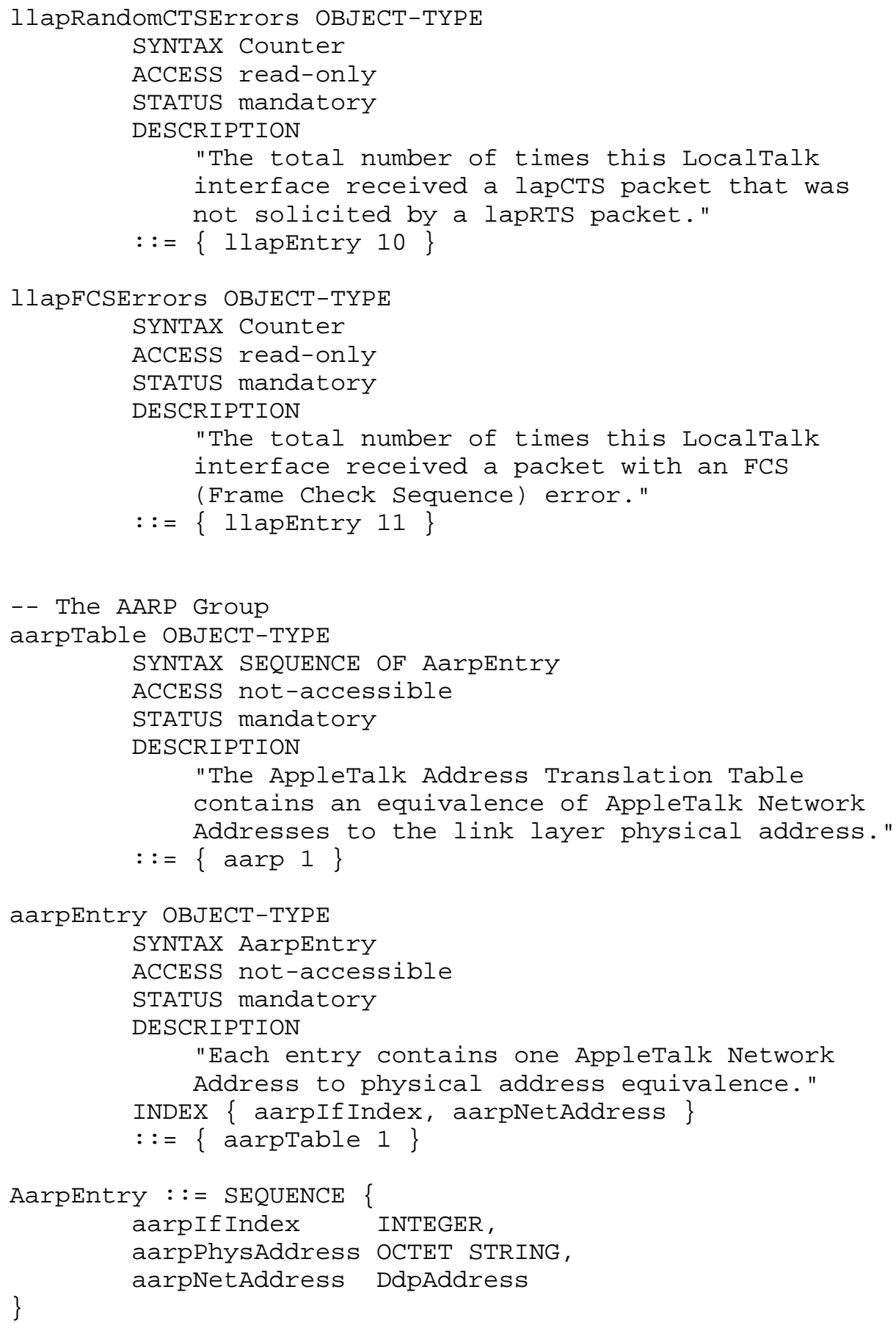




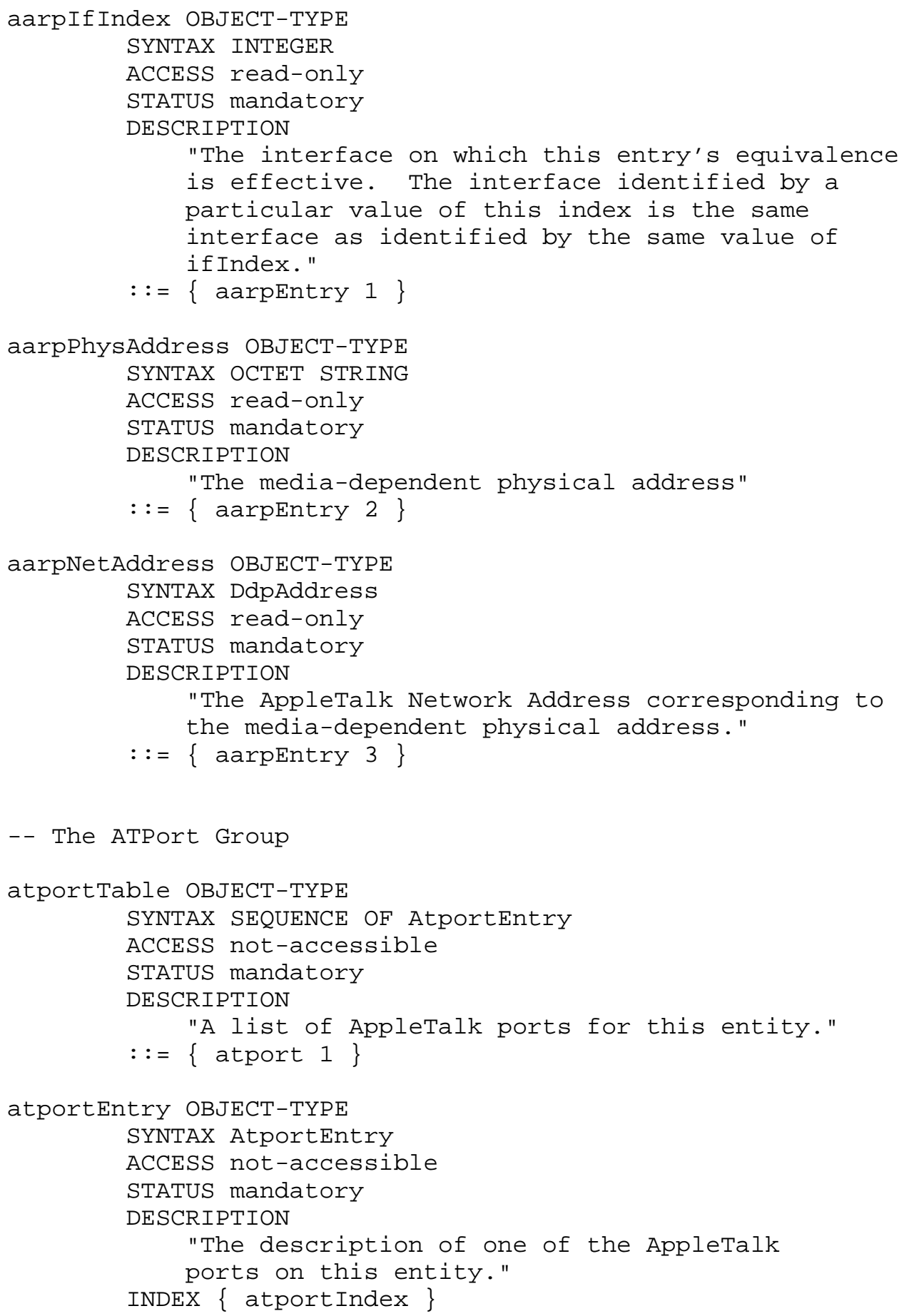




$$
::=\{\text { atportTable } 1\}
$$

AtportEntry : := SEQUENCE \{ atportIndex atportDescr atport Type

INTEGER, atportNetstart DisplayString, atportNetEnd INTEGER, OCTET STRING (SIZE(2)), atportNetAddress atportstatus OCTET STRING (SIZE (2)), atportNetConfig DdpAddress, atportzoneconfig INTEGER, INTEGER, atportzone

\}

atportifIndex INTEGER, OCTET STRING, INTEGER

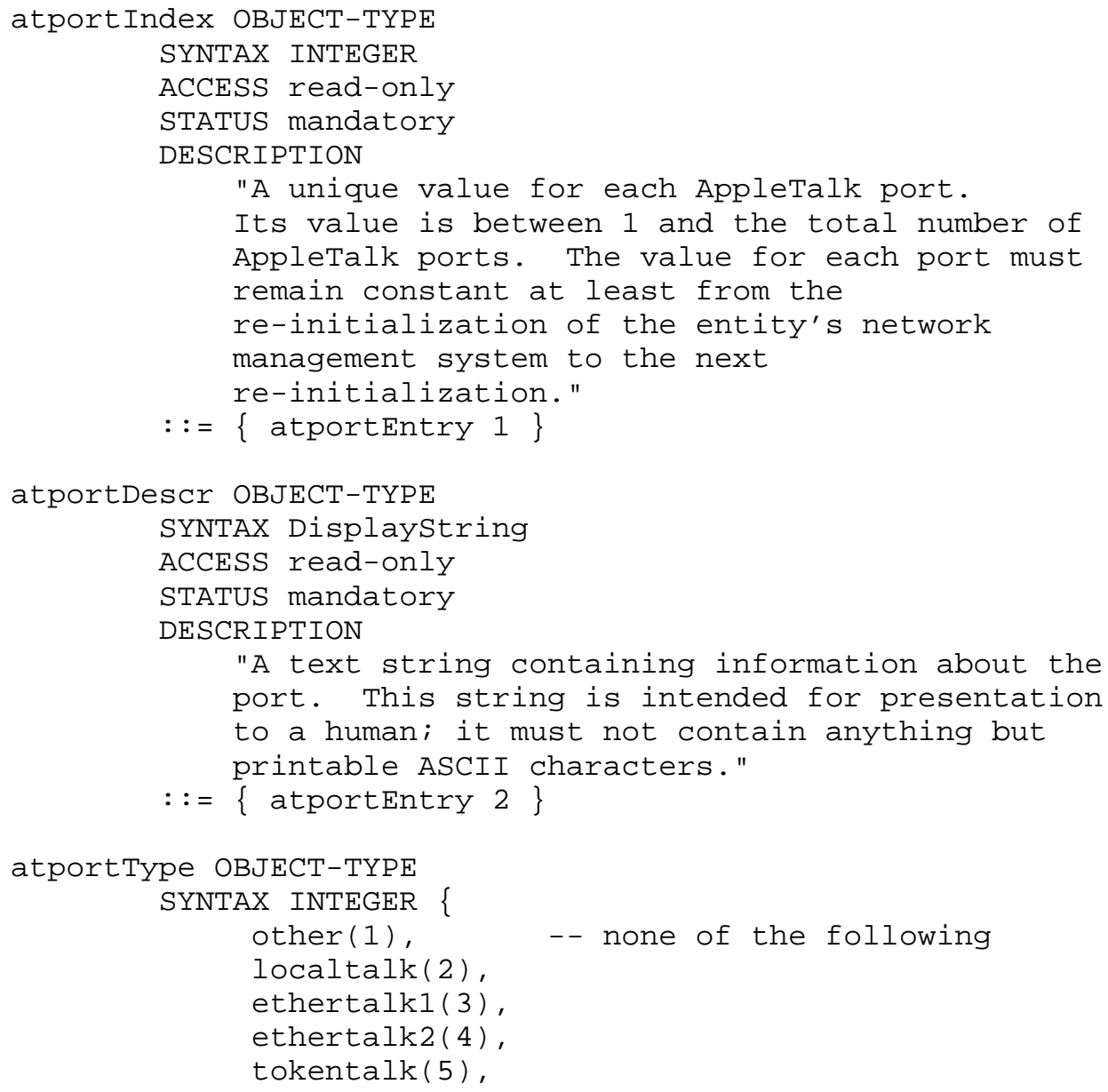




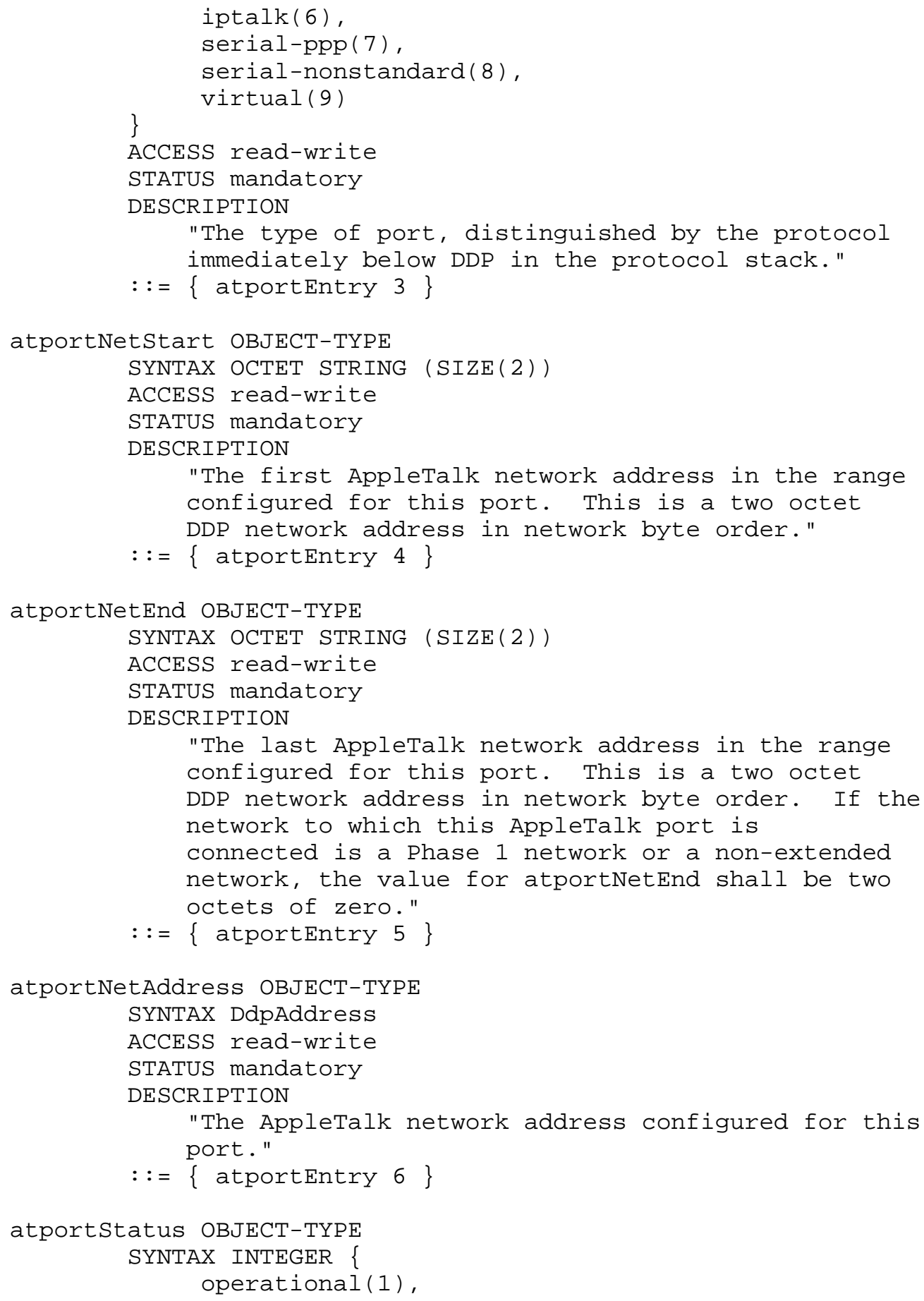




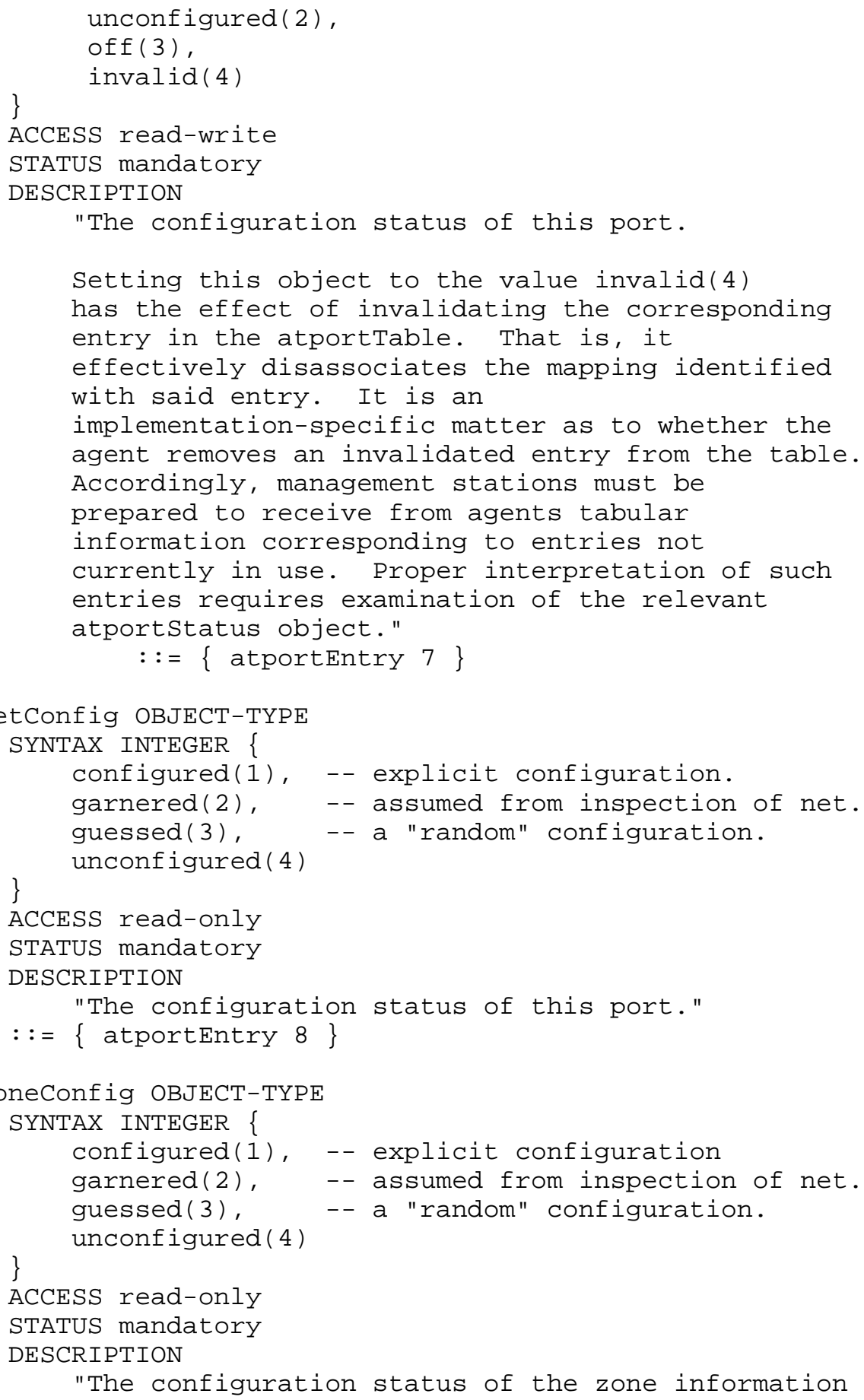




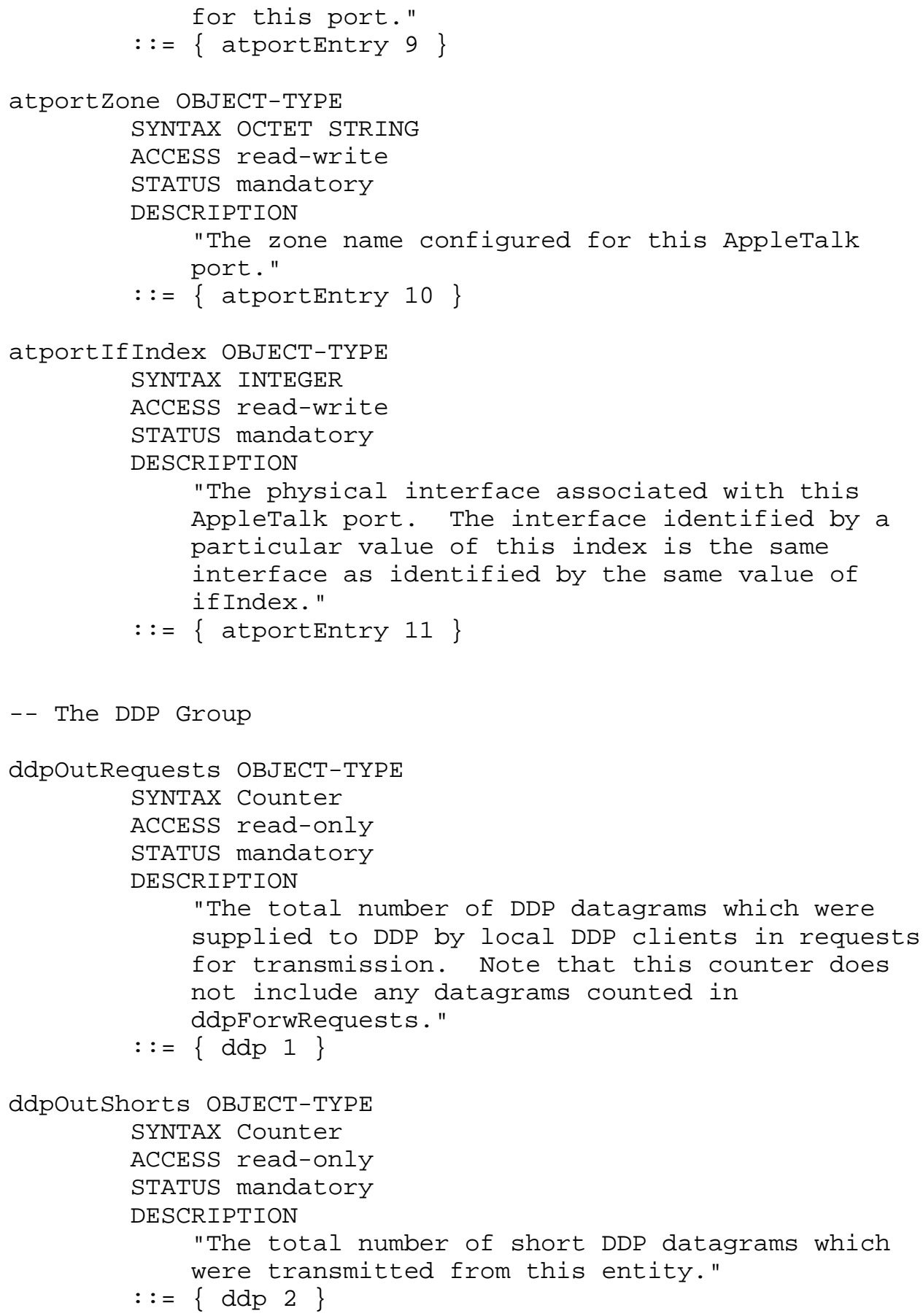




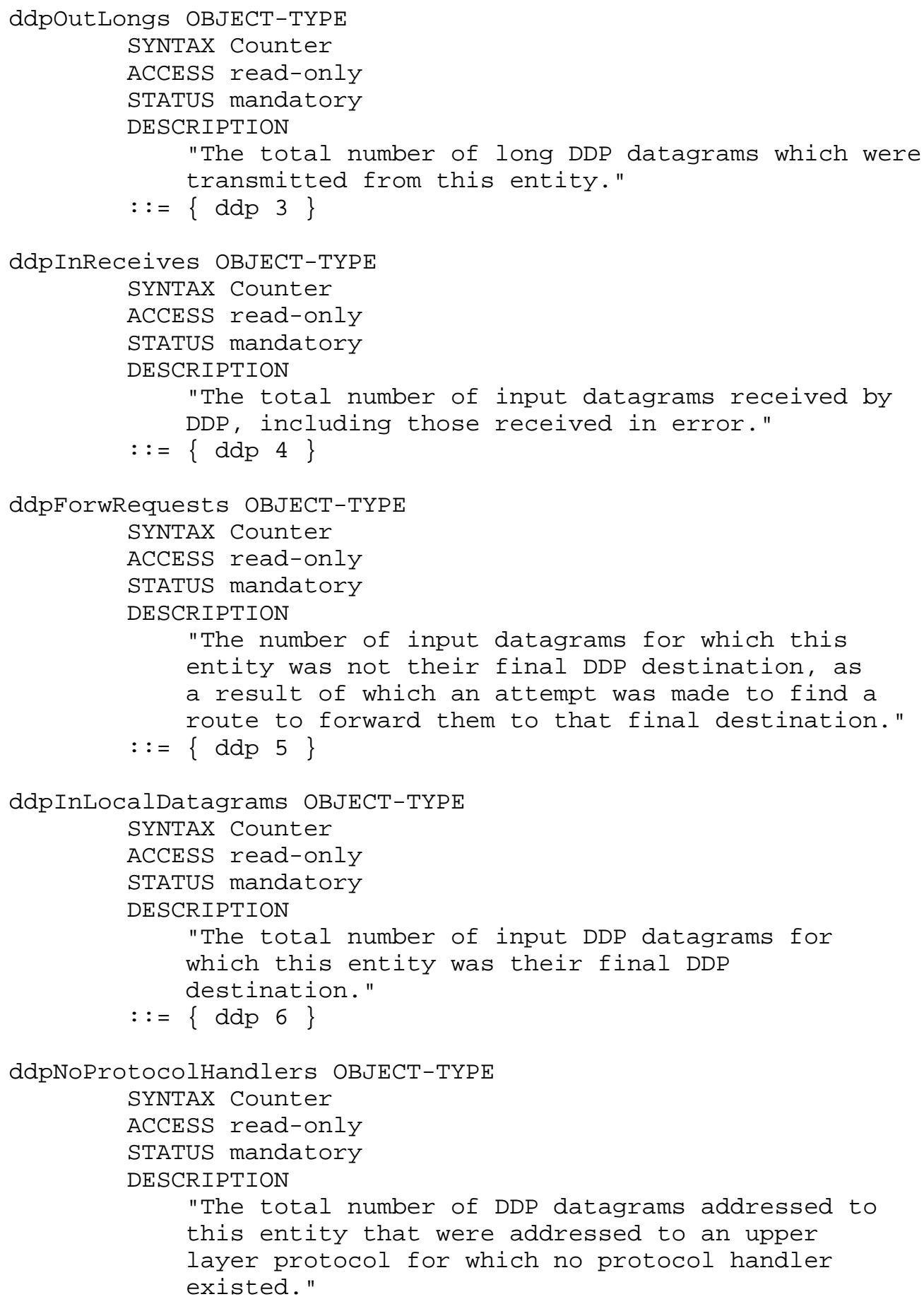




$$
::=\{\operatorname{ddp} 7\}
$$

ddpOutNoRoutes OBJECT-TYPE

SYNTAX Counter

ACCESS read-only

STATUS mandatory

DESCRIPTION

"The total number of DDP datagrams dropped

because a route could not be found to their

final destination."

$::=\{\operatorname{ddp} 8\}$

ddpTooShortErrors OBJECT-TYPE

SYNTAX Counter

ACCESS read-only

STATUS mandatory

DESCRIPTION

"The total number of input DDP datagrams dropped

because the received data length was less than

the data length specified in the DDP header or

the received data length was less than the

length of the expected DDP header."

$::=\{\operatorname{ddp} 9\}$

ddpTooLongErrors OBJECT-TYPE

SYNTAX Counter

ACCESS read-only

STATUS mandatory

DESCRIPTION

"The total number of input DDP datagrams dropped

because the received data length was greater

than the data length specified in the DDP header or because they exceeded the maximum DDP datagram size."

$::=\{\operatorname{ddp} 10\}$

ddpBroadcastErrors OBJECT-TYPE

SYNTAX Counter

ACCESS read-only

STATUS mandatory

DESCRIPTION

"The total number of input DDP datagrams dropped because this entity was not their final

destination and they were addressed to the link

level broadcast."

$::=\{\operatorname{ddp} 11\}$ 


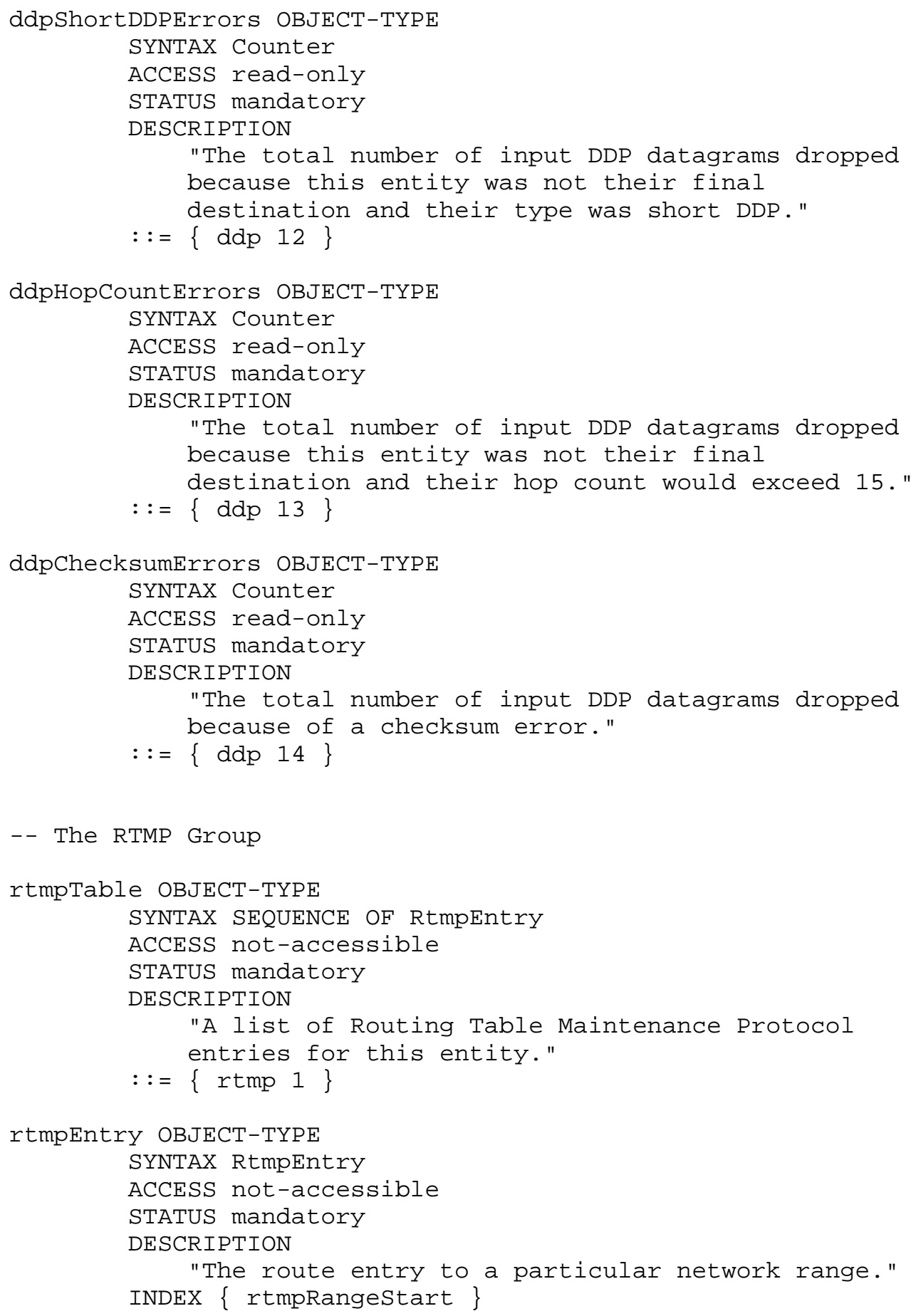




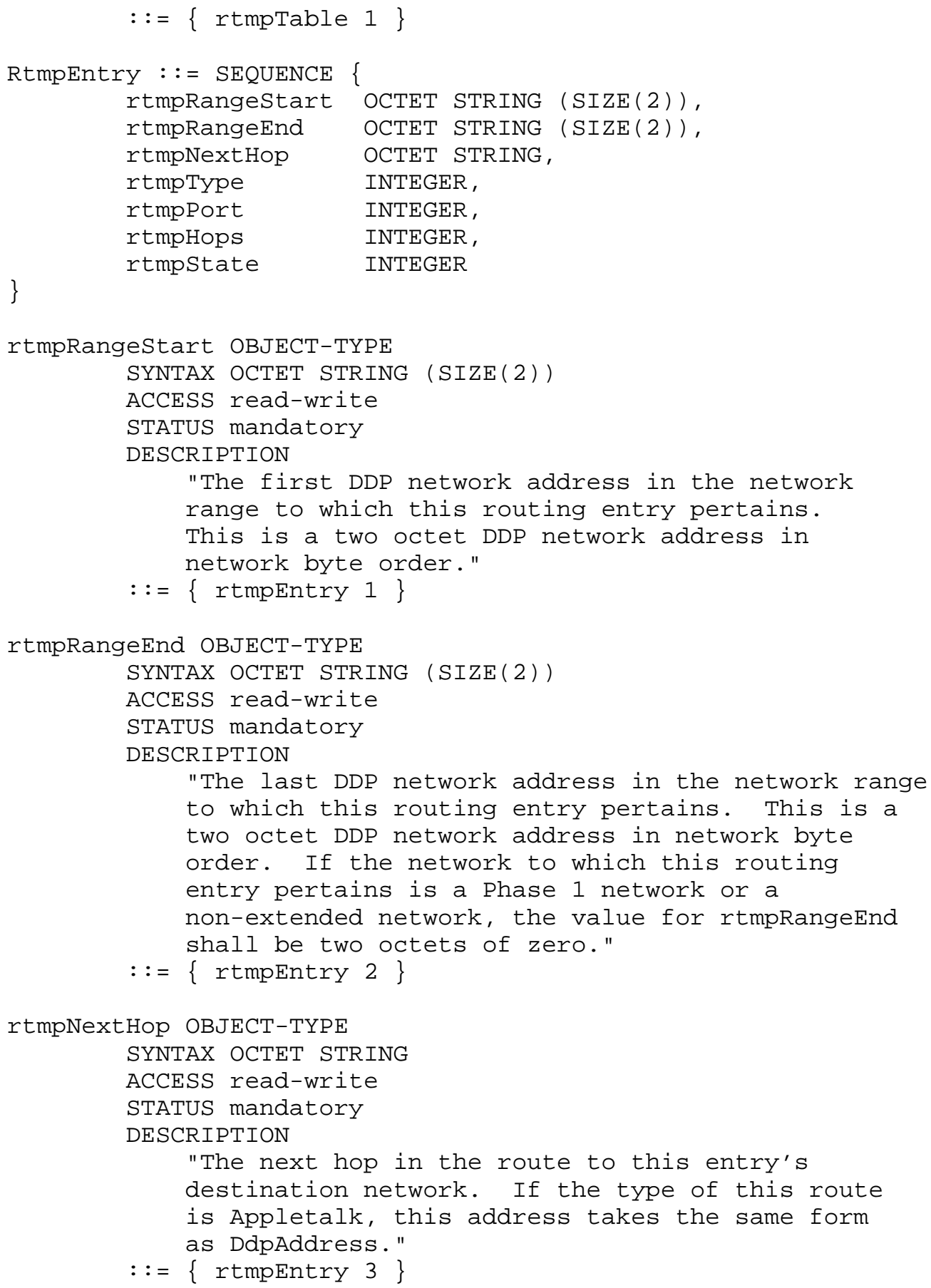




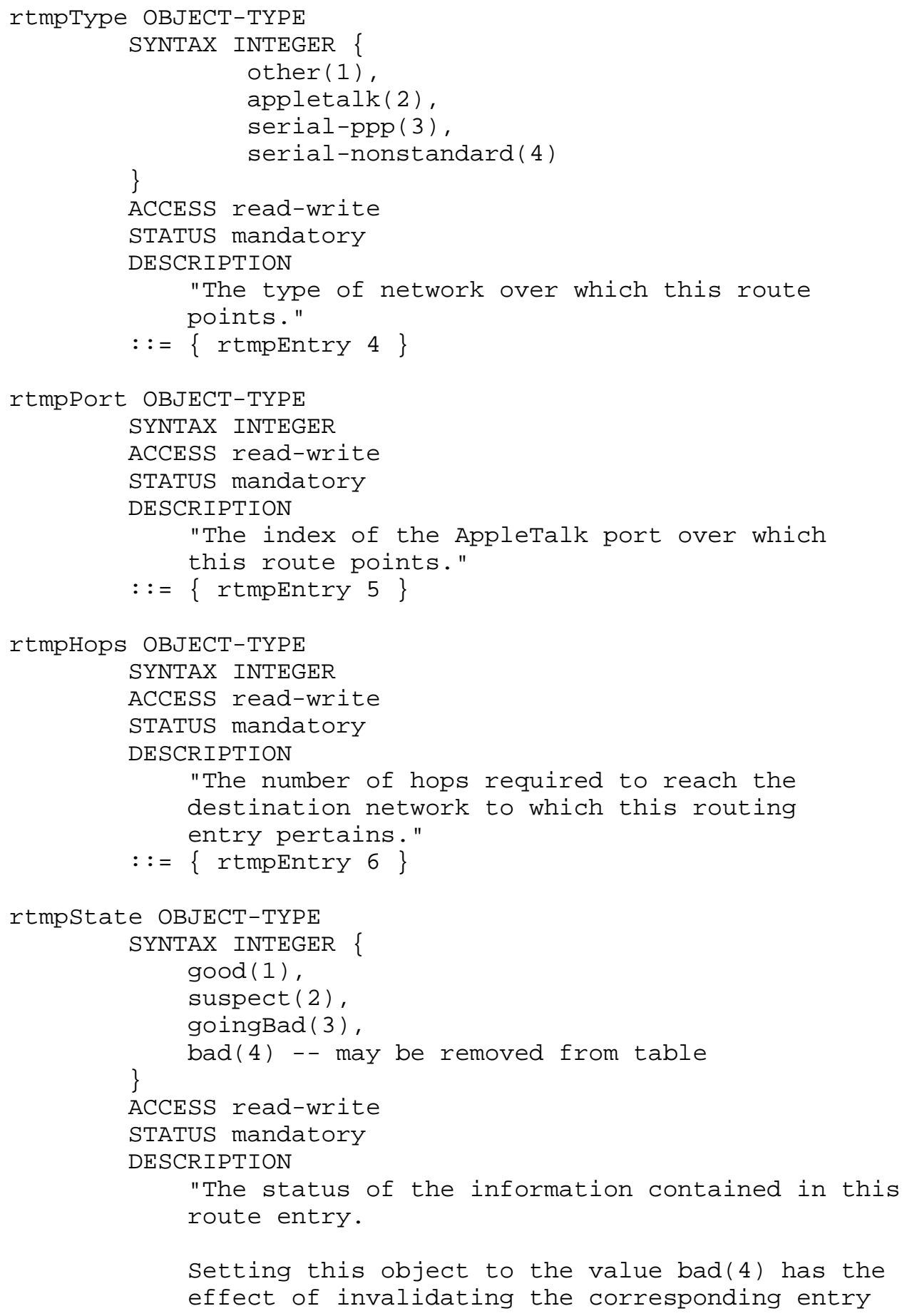




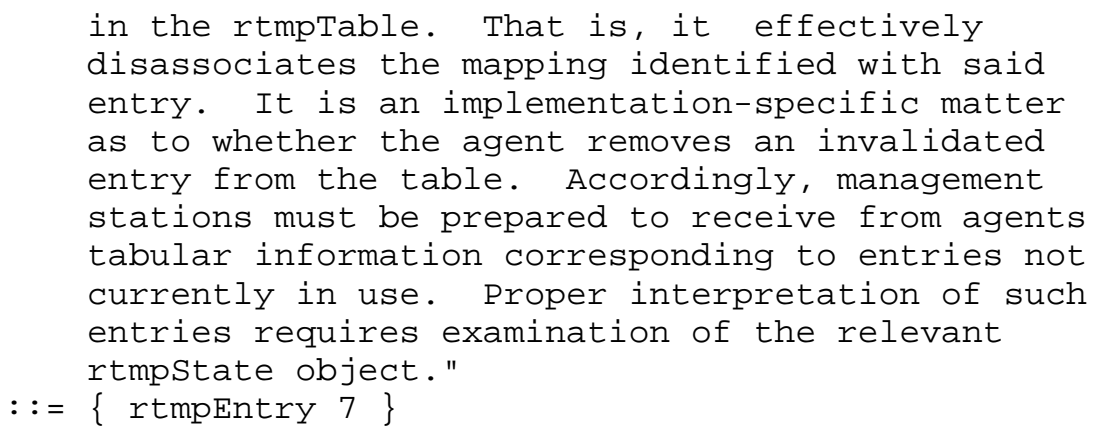




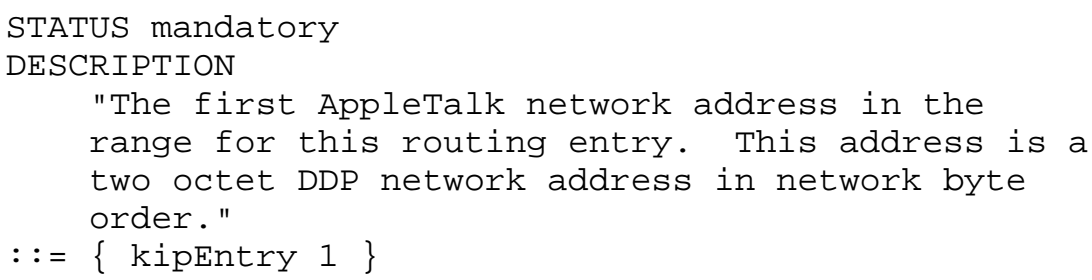




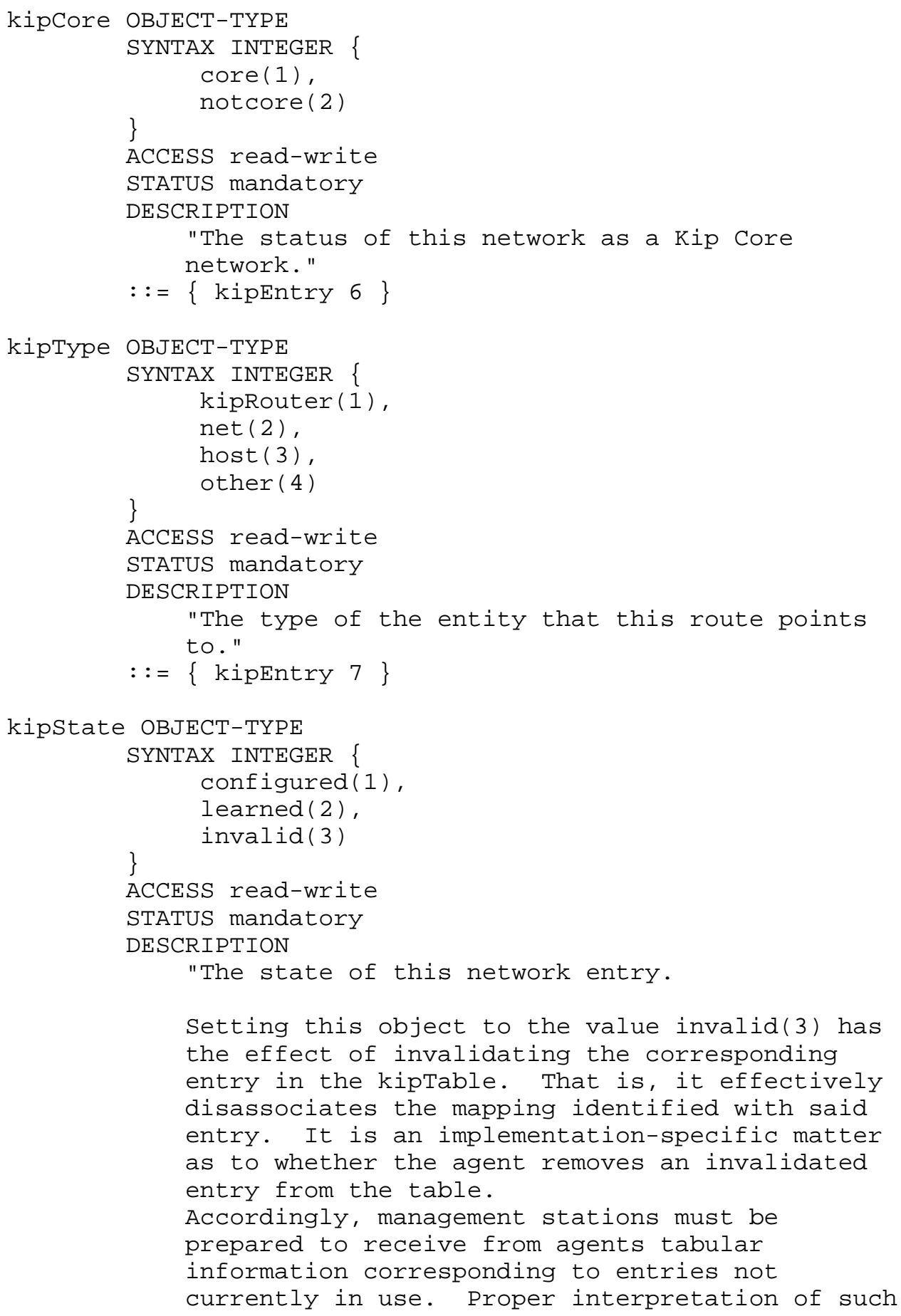




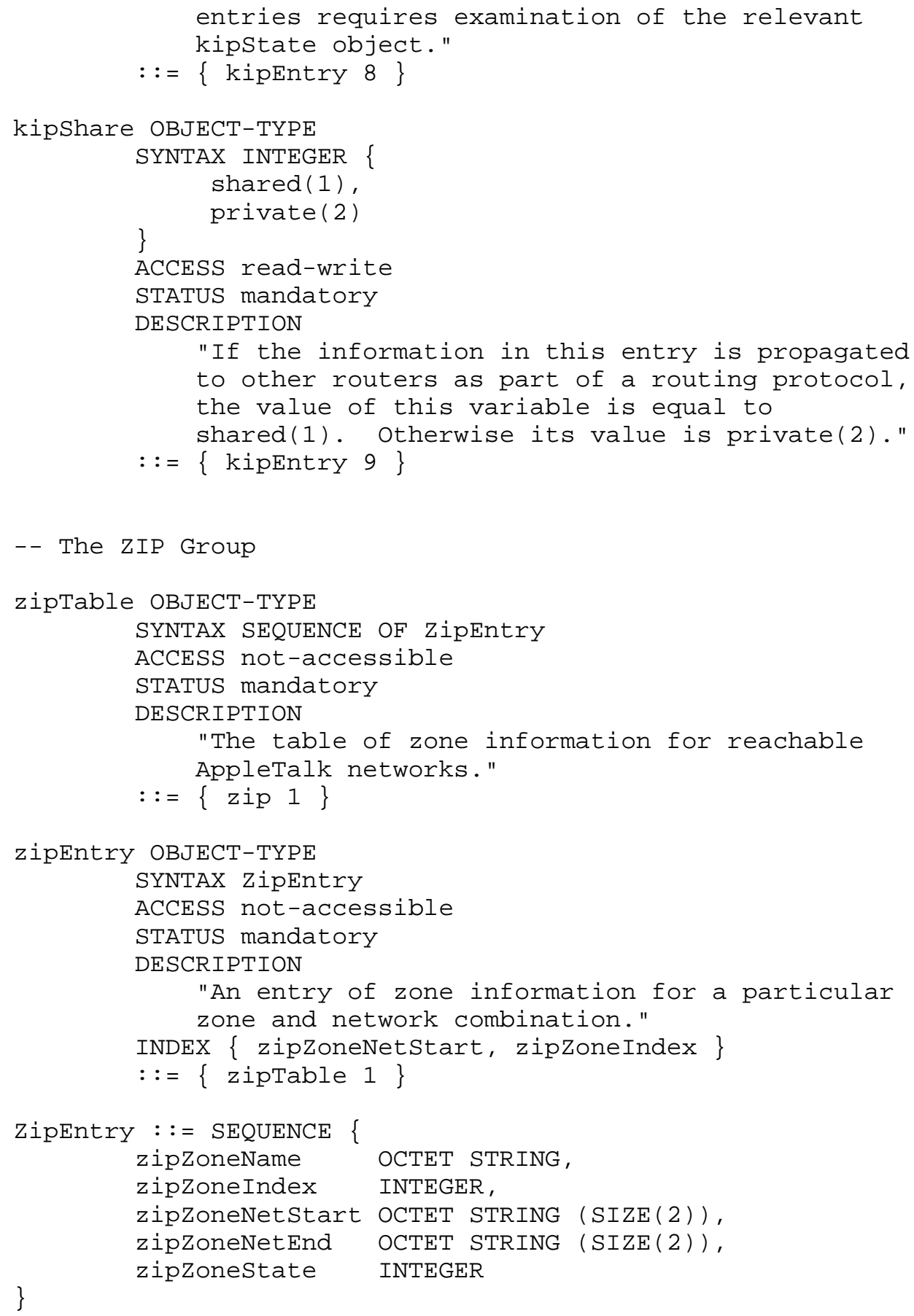




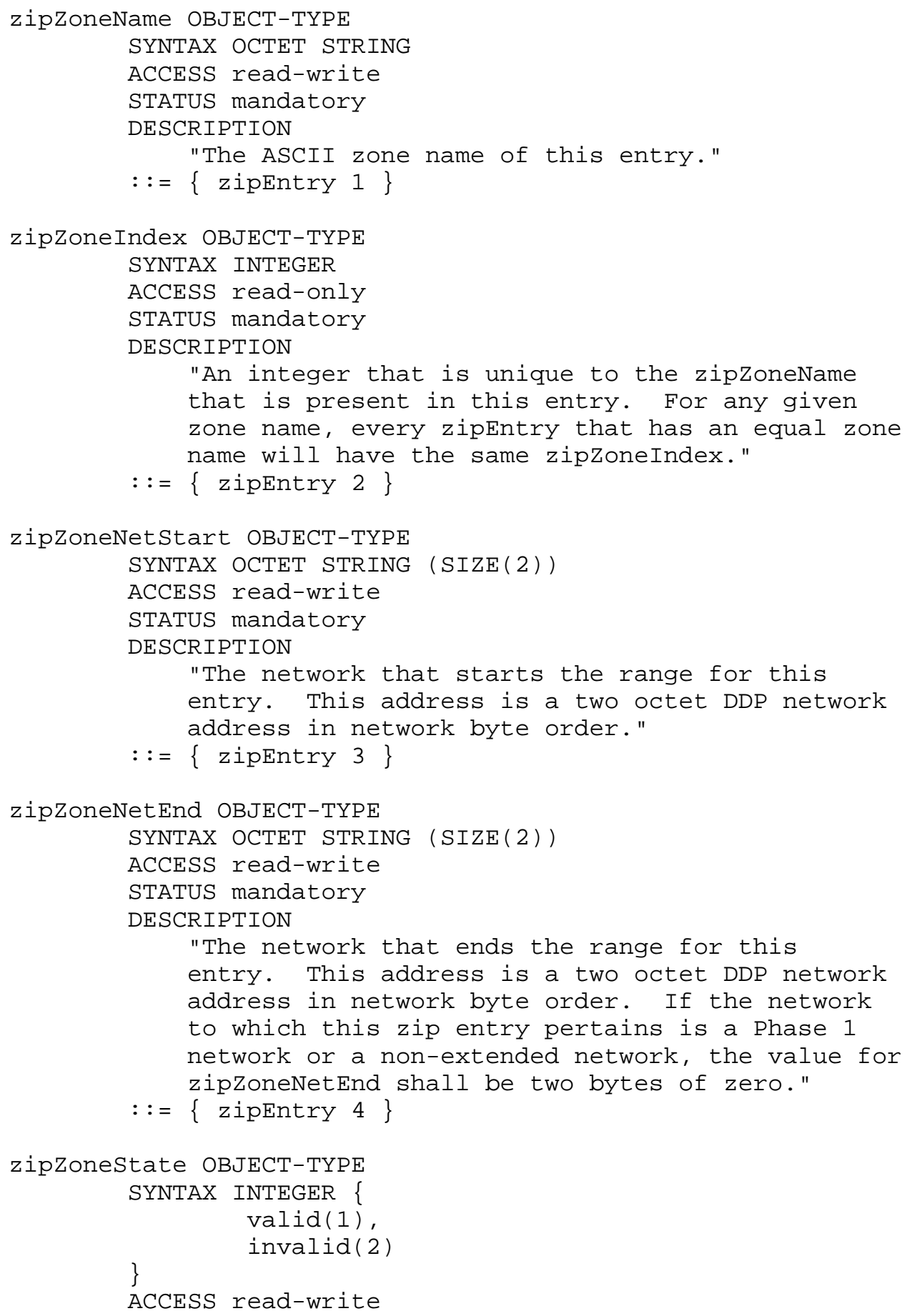




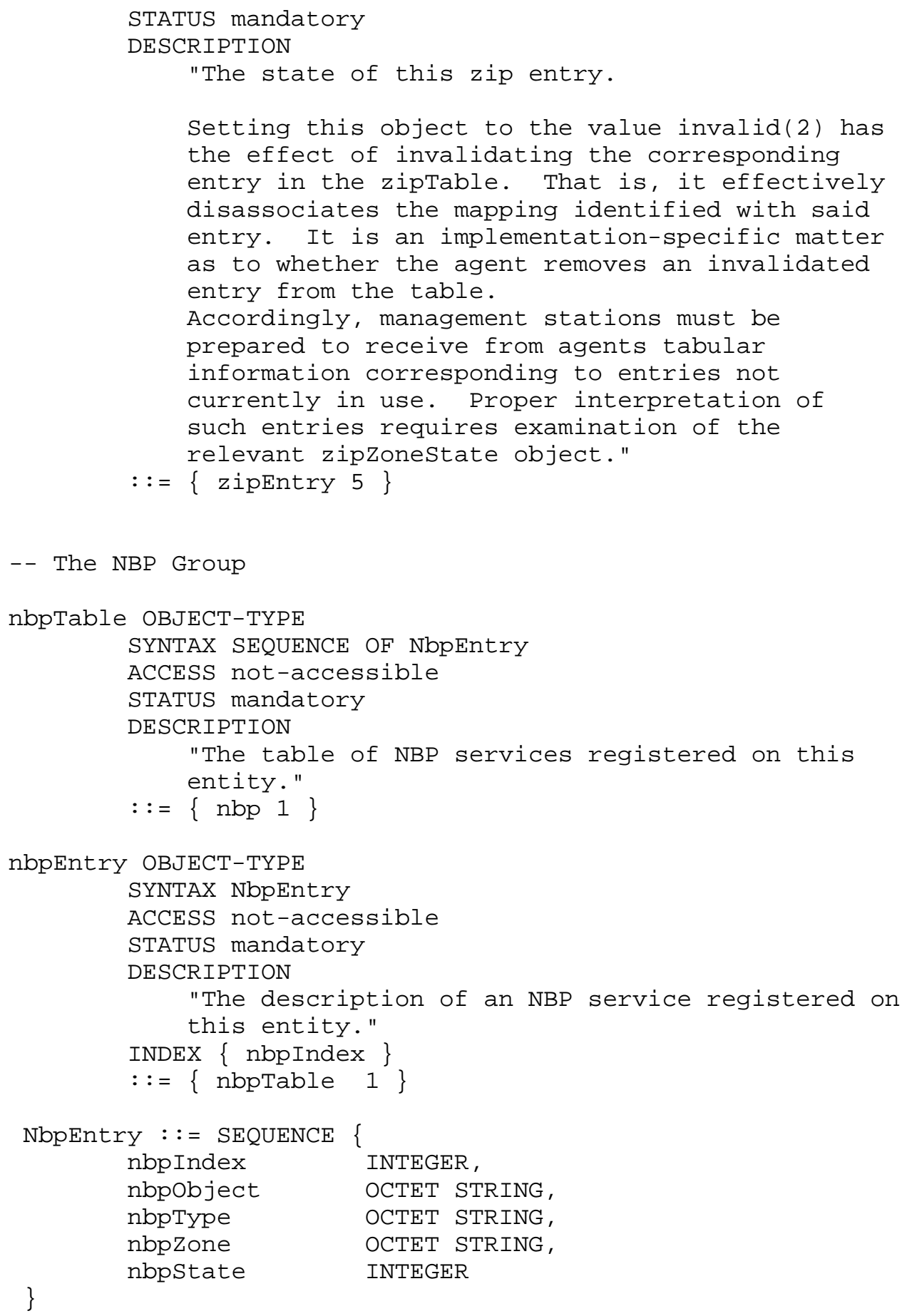




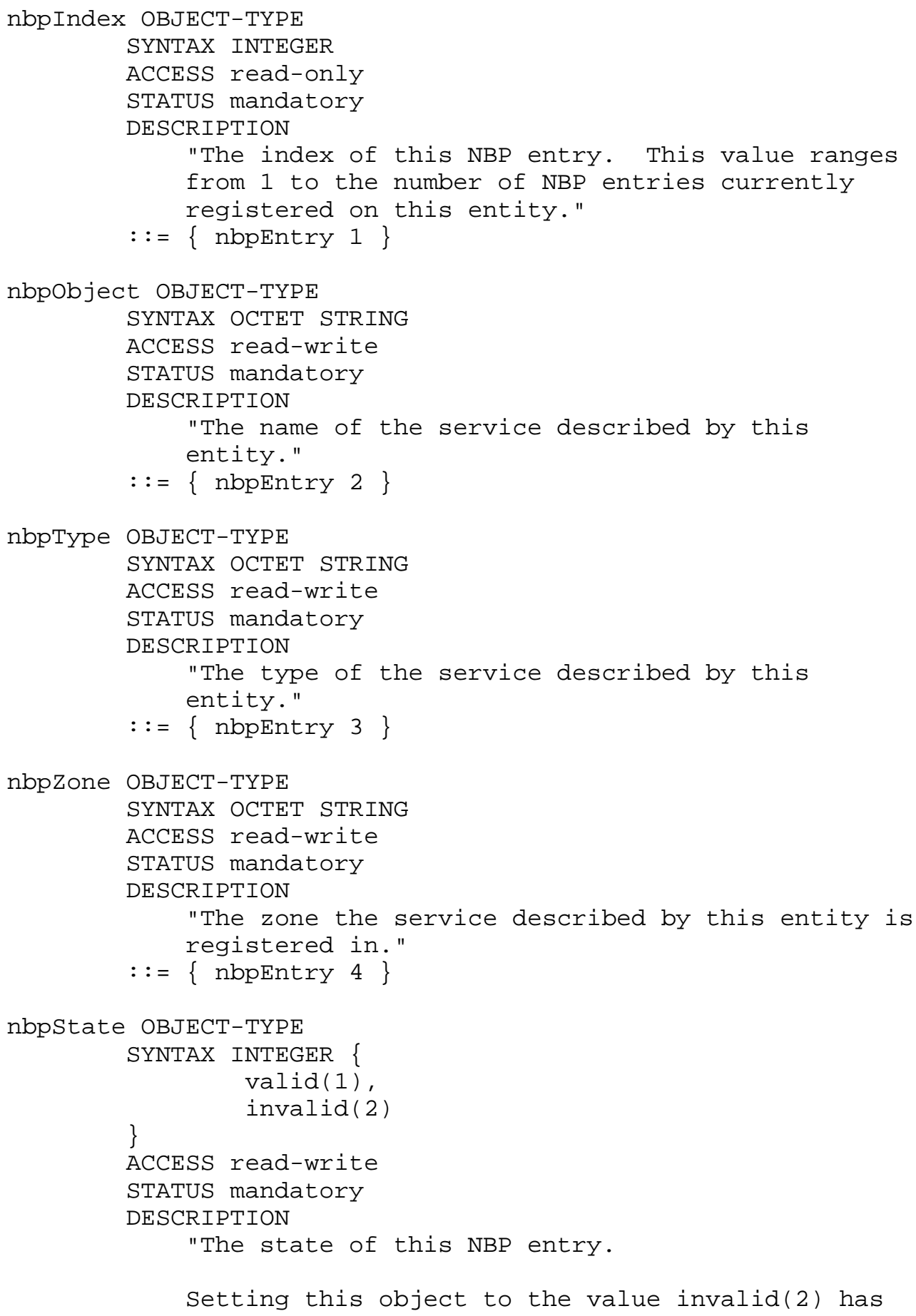




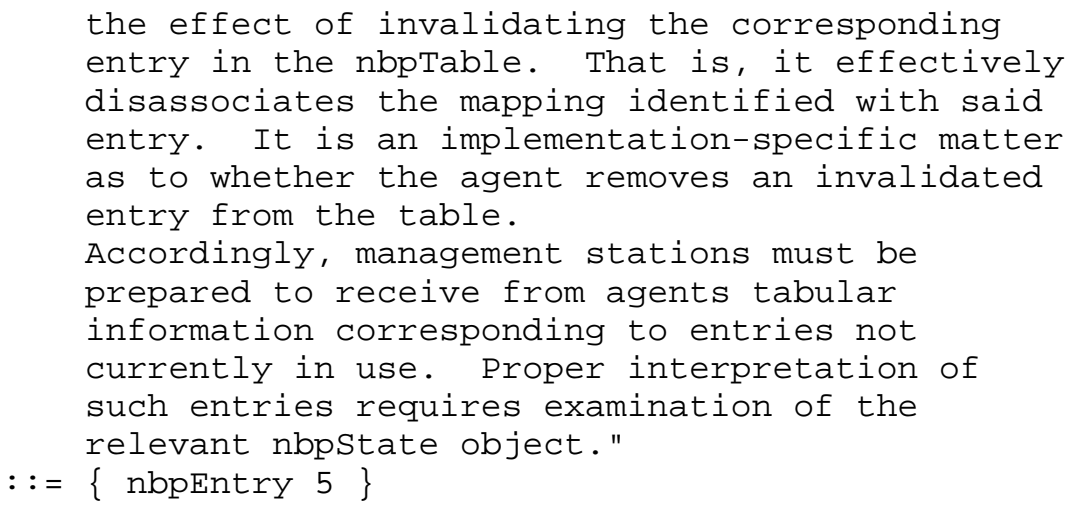

6. Acknowledgements

This document was produced by the IETF AppleTalk-IP Working Group:

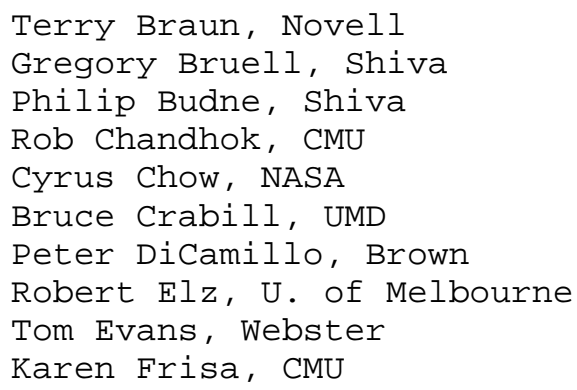




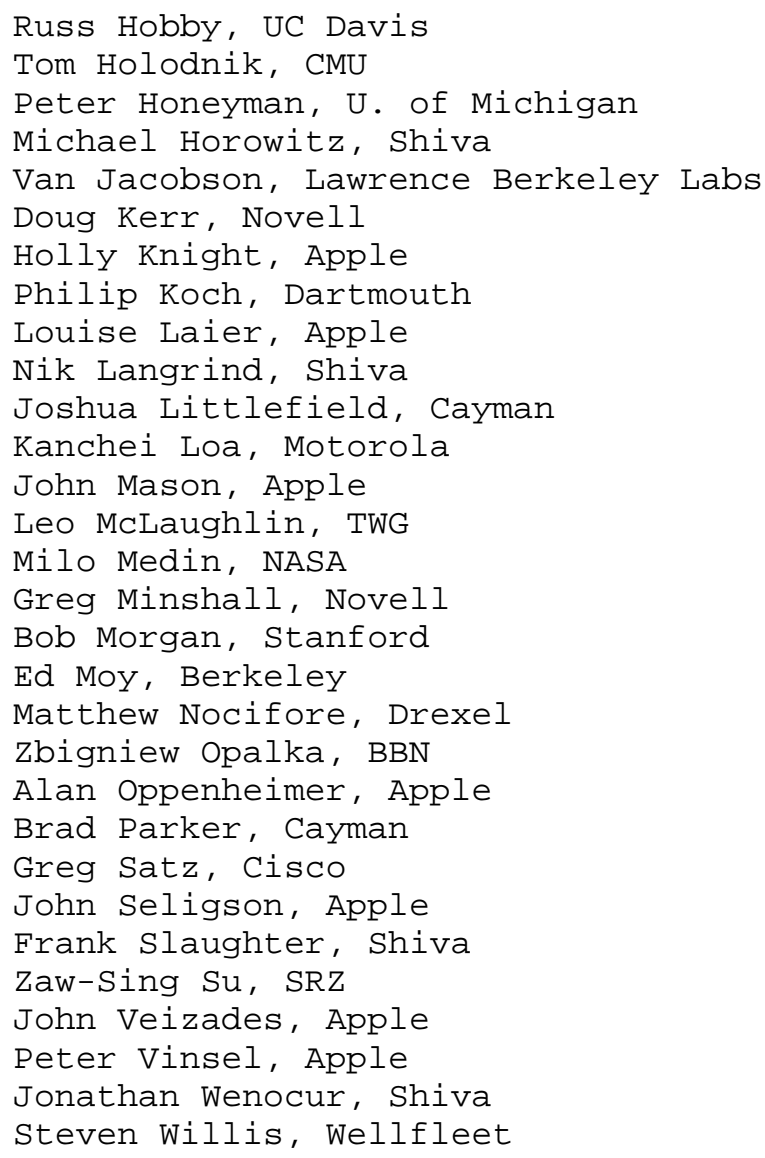

In addition, the contribution of the following individuals is also acknowledged:

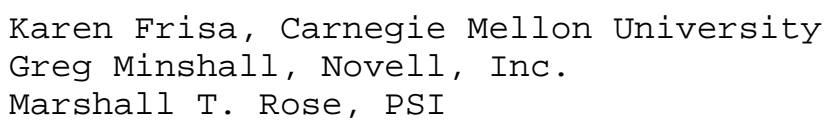

7. References

[1] Cerf, V., "IAB Recommendations for the Development of Internet Network Management Standards", RFC 1052, NRI, April 1988.

[2] Cerf, V., "Report of the Second Ad Hoc Network Management Review Group", RFC 1109, NRI, August 1989.

[3] Rose M., and K. McCloghrie, "Structure and Identification of Management Information for TCP/IP-based internets", RFC 1155, 
Performance Systems International, Hughes LAN Systems, May 1990.

[4] MCCloghrie K., and M. Rose, "Management Information Base for Network Management of TCP/IP-based internets", RFC 1156, Hughes LAN Systems, Performance systems International, May 1990.

[5] Case, J., Fedor, M., Schoffstall, M., and J. Davin, "Simple Network Management Protocol", RFC 1157, SNMP Research, Performance Systems International, Performance Systems International, MIT Laboratory for Computer Science, May 1990.

[6] McCloghrie K., and M. Rose, Editors, "Management Information Base for Network Management of TCP/IP-based internets", RFC 1213, Performance Systems International, March 1991.

[7] Information processing systems - Open systems Interconnection Specification of Abstract Syntax Notation One (ASN.1), International Organization for Standardization, International Standard 8824, December 1987.

[8] Information processing systems - Open Systems Interconnection Specification of Basic Encoding Rules for Abstract Notation One (ASN.1), International Organization for Standardization, International Standard 8825, December 1987.

[9] Rose, M., and K. McCloghrie, Editors, "Concise MIB Definitions", RFC 1212, Performance Systems International, Hughes LAN Systems, March 1991.

[10] Sidhu, G., Andrews, R., and A. Oppenheimer, "Inside AppleTalk", Second Edition, Addison Wesley, 1990.

8. Security Considerations

Security issues are not discussed in this memo.

9. Author's Address

Steven Waldbusser

Carnegie Mellon University

4910 Forbes Ave.

Pittsburgh, PA 15213

EMail: waldbusser@andrew.cmu.edu 